\section{A obscenidade do cotidiano e a cena comunicacional contemporânea*}

\section{RESUMO}

Está cada vez maior o interesse contemporâneo pelo comum e pela banalidade do cotidiano, o que se traduz pela exposição do ser em diversos níveis e formatos de visibilidade, como na internet e na televisão. As íntimas relações entre o cotidiano, a aparência, 0 artifício e a efemeridade encontram no ambiente comunicacional um exemplo extremo e grotesco, despertando fascínio e interesse em milhões de espectadores.

\section{ABSTRACT}

This text says there is in contemporaneity a strong interest for the vulgar and the banal, as we can observe all over internet and television. There are intimate relationships among daily life, appearance, artifacts and ephemera as shown by those media, which fascinate and grabs the attention of their million of users.

\section{PALAVRAS-CHAVE (KEY WORDS)}

- Cotidiano (Daily life)

- Visibilidade (Visibility)

- Pós-modernidade (Postmodernity)

\section{Fernanda Bruno}

Prof. Programa Pós-Graduação em Comunicação/UFRJ Coordenadora do CiberIDEA: Núcleo de Pesquisa em tecnologia, cultura e subjetividade.
"Sabendo integrar, de um ponto de vista epistemológico, a experiência sensível espontânea que é a marca da vida cotidiana, a progressão intelectual poderá, assim, reencontrar a interação da sensibilidade e da espiritualidade própria por exemplo, da sensibilidade es da espiritualidade, propria, por exemplo, ao barroco, e assim alcançar, atraves da aparencia, a profundidade das maneiras de ser e dos modos de vida pós-modernos que, de múltiplas maneiras, põem em jogo estados emocionais e 'apetites' passionais que repousam, largamente, sobre a iluminação dos sentidos".

(Maffesoli, M. - Elogio da Razão Sensível).

A SENSIBILIDAde DO PENSAMENTO de Maffesoli aos modos de existência e às práticas pós-modernas encontra na sua atenção conferida ao cotidiano um dentre muitos exemplos. Se considerarmos a cena comunicacional contemporânea, ambiente privilegiado de constituição da sociabilidade e das subjetividades pós-modernas, notamos sem muito esforço um interesse patente pelo cotidiano. A explosão de reality shows das mais diversas naturezas na televisão, a forte presença da produção documental no cinema contemporâneo, o recente fenômeno dos weblogs, webcams, fotologs e do Orkut na Internet, o espraiamento dos dispositivos de vigilância eletrônica - todos estes 'fenômenos' nos revelam um cotidiano profusamente exposto, olhado, documentado, publicizado, vigiado, espreitado. Certamente os casos mencionados portam as suas especificidades e não nos revelam um mesmo e único cotidiano. No entanto, todos eles apontam para o que se deseja ressaltar e explorar neste ensaio: o cotidiano como lugar de extrema visibilidade na atualidade. Esse lugar comum, ordinário, geralmente deixado no anonimato e na sombra ganha notoriedade e torna-se foco de múltiplos olhares.

A apreensão deste fenômeno encontra na obra de Maffesoli potentes instrumentos de análise na medida em que o autor 'dignifica' o cotidiano e todas as suas características ordinárias como objetos privilegiados de investigação e reflexão sobre a constituição mesma da vida social (Cf. 1998c).

“A sociologia, aprendida unicamente nos livros, em geral não experimenta interesse algum por todas as coisas banais que fazem a vida efetiva das pessoas, apressada que está em ela- 
borar categorias abstratas que fazem o delírio dos debates de escola e, por repercussão, dos artigos jornalísticos ou dos relatórios administrativos. Assim, ignorando-se as diversas manifestações do senso comum, deixa-se oculta a maior parte da vida cotidiana que, verdade seja dita, tem bem pouca coisa a ver com os sistemas teóricos que repousam, essencialmente, em entidades abstratas" (Maffesoli, 1998b, p. 166).

Além disso, o autor nos revela a atualidade deste tema, que se constitui como um dos traços da pós-modernidade. "Por mais que isso horrorize os criticos politicamente corretos, as pessoas não querem só informação na mídia, mas também e fundamentalmente ver-se, ouvir-se, participar, contar o próprio cotidiano para si mesmas e para aqueles com quem convivem" (Maffesoli, 2004, p. 23). Neste sentido, o autor nos conduz e nos inspira a interrogar o que o interesse contemporâneo pelo comum e pela banalidade do cotidiano, interesse que se traduz pela sua exposição em diversos níveis e formatos de visibilidade, nos diz sobre esses nossos tempos pós-modernos, a sociabilidade e as subjetividades que aqui se produzem? Esta questão pode ser encaminhada e explorada, ainda que de modo breve e parcial, pela análise de algumas práticas e dispositivos comunicacionais recentes, como os reality shows televisivos, os weblogs, fotologs ${ }^{1}$ e o Orkut ${ }^{2}$ na Internet.

A característica mais evidente destas práticas e dispositivos é sua extrema mediocridade - de um modo geral, tanto as suas escolhas formais quanto os seus conteúdos são muito próximos do ridículo. É comum nos sentimos envergonhados por estarmos testemunhando cenas, pequenos dramas e conversações tão ordinárias. No entanto, este mesmo terreno de banalidades pode nos revelar algo sobre o modo como estamos tecendo nossa cotidianeidade, nossa subjetividade e nossa relação com o olhar do outro. Como mostra Maffesoli (1998c; 2000; 2004), a crítica que rapidamen- te põe em obra uma lógica do dever-ser e da denúncia de manipulação impede que se apreenda a ambigüidade dos fenômenos sociais e comunicacionais, que muitas vezes nos revelam mais 'verdades' que ilusões e encarnam, naquilo que têm de mais superficial, frívolo e banal, os processos reais e concretos da existência social na contemporaneidade. Adotemos aqui esta perspectiva e esta sensibilidade diante dos ambientes comunicacionais mencionados.

Um primeiro aspecto a considerar é o caráter exposto, explícito e mesmo obsceno do cotidiano. Nos ambientes comunicacionais em questão, a vida cotidiana assume uma expressão prioritariamente superficial e visível ao olhar do outro. Se a Modernidade produziu uma topologia do cotidiano que circunscrevia o espaço privado e seus diversos níveis de vida interior - casa, família, intimidade, psiquismo - a pós-modernidade inverte esta topologia e volta o cotidiano para espaço aberto dos meios de comunicação e seus diversos níveis de vida exterior - tela, imagem, interface, interatividade. Ao mesmo tempo, a escala ótica do cotidiano encontra-se transformada. Aos espaços interiores e privados da modernidade correspondia um regime de visibilidade que guardava regiões de sombra e de opacidade onde se recolhiam e se associavam o secreto e o autêntico, o recôndito e o verdadeiro. A natureza recôndita da verdade do sujeito moderno guarda muitas vezes um parentesco com a sua natureza opaca, invisível não apenas ao olhar do outro, mas também ao próprio sujeito. A problemática do inconsciente e os diversos saberes e terapêuticas 'psi' participam ativamente da constituição desta verdade tão mais 'autêntica' quanto menos visível e dizível. A posição privilegiada que a sexualidade ocupa nas concepções médicas e psicológicas de doença mental também ilustra esta identificação da verdade com a porção simultaneamente mais secreta e determinante do sujeito. Um outro exemplo é o diário íntimo, que ocupa um lugar importante na narrativa e decifração cotidiana do eu e de seus segredos in- 
confessáveis. Nas práticas contemporâneas de exposição do eu - reality shows, weblogs, webcams, fotologs e Orkut - a autenticidade encontra-se vinculada não mais ao opaco e ao recôndito mas sim à dimensão visível e acessível ao olhar do outro. Inúmeros relatos de bloggeiros (Cf. Recuero, 2003a e Lemos 2001) e de participantes de reality shows (Cf. Ehrenberg, 1995) mostram que os indivíduos crêem que suas vidas comuns e banais, seus dramas pessoais e seu cotidiano ganham alguma efetividade, consistência e verdade no ato mesmo de se mostrar ao outro. Eis talvez uma das razões do caráter promíscuo e quase pornográfico destas encenações de si e do cotidiano. Ora, este sentido de autenticidade, tão estranho a certos referenciais modernos, pode ser melhor compreendido se articularmos esse regime de visibilidade do cotidiano e da subjetividade com um outro tema, também caro a Maffesoli (1996) - o primado da aparência.

"Il est des situations et des lieux qui ont échappé à l'injonction de la profondeur, qui se sont contentés d'être tout en surface, et, ainsi, d'être les conservatoires de la globalité, du qualitatif. Le quotidien et son 'pré-sentéisme' en sont un bon exemple. L'ambience affectuelle qui le ca-ractérise repose sur l'apparence, sur une vie qui se donne à voir. Le 'voyeurisme', pour le meilleur et pour le pire, est en ce sens un bon vecteur de socialité. Le quotidien n'exclut pas l'emotion ou l'affect, ne les cantonne pas dans la sphère du privé. Il les théâtralise, en fait une éthique de l'esthétique" (Maffesoli, 2000, p. 153).

As subjetividades e identidades pósmodernas, na medida em que se afastam da tópica moderna que privilegiava a profundidade e a interioridade como dimensões autênticas e verdadeiras, parecem não mais obedecer à lógica que associa a aparência e a superficialidade aos domínios do engodo, do falso, da mentira, da manipulação. Ou melhor, o lugar onde o eu se realiza e se efetiva é na proximidade do olhar do outro, na sua potencialidade de ser visto, e não mais no recolhimento de uma interioridade sombreada e relativamente opaca. A sua face visível, exterior não é apenas o reino do outro, onde sempre é possível mascarar ou mentir, mas também e conjuntamente o reino do próprio eu, da persona que só existe na relação com o outro (Maffesoli, 1998a). De outro lado, o espaço íntimo, interior e privado, deixa de ser experimentado como a morada mesma da verdade, de uma realidade autêntica onde o engodo só é possível malgrado o próprio sujeito.

Estamos aqui talvez mais próximos das subjetividades 'pré-modernas', cujas marcas de civilidade e sociabilidade residiam na aparência e no imediatamente visível. Neste sentido, o culto contemporâneo da aparência indicaria não tanto a exacerbação do narcisismo e do individualismo, mas da socialidade. Conforme Maffesoli, "insister sur l'intime liaison existant entre voir, être vu, vivre, n'est pas anodin, en un moment, justement, où l'image longuement stigmatisée (re)devient un des pivots de la vie sociale ... l'apparence est rien moins qu'individualiste. Bien au contraire, elle se construit sous e pour le regard de l'autre" (2000, pp. 134-146). É possível contudo argumentar que uma radicalização do individualismo pode ir de par com a atual exposição de si ao olhar do outro; e talvez esta seja uma das ambigüidades da pós-modernidade. De toda maneira, o autor enuncia o que nos interessa de fato ressaltar. Os cuidados com a aparência e a conquista do olhar do outro estão cada vez mais atrelados à constituição do eu como imagem. Não é por acaso que a cena comunicacional - da TV a Internet - torna-se palco da sociabilidade e da produção de subjetividades contemporâneas.

Vale notar que esta cena não mais se identifica plenamente a um espaço onde a realidade e uma pequena elite célebre se oferecem a uma massa de indivíduos comuns na forma de imagens espetaculares 
entregues em domicílio, pautando a sua cotidianeidade. Doravante, seja nos reality shows ou nos weblogs, um outro sonho se anuncia: o indivíduo comum é chamado a ocupar o outro lado da tela e a passar de consumidor de imagens a ator de sua própria vida e de seu próprio cotidiano, naquilo mesmo que ele tem de mais vulgar, corriqueiro e ordinário. A este indivíduo é requerido que represente a si mesmo e encene a sua autenticidade. E aquele que por ora está na condição de espectador é chamado a participar ativamente - o princípio de interatividade atua fortemente na constituição da almejada 'proximidade' com o espectador e do 'efeito de realidade' produzido nestas novas modalidades de exposição de si. Se o eu se constitui na imagem e como imagem, é preciso que ele tome para si seus atributos contemporâneos, ampliando a sua margem de interatividade. $\mathrm{O}$ eu-imagem deve ser reativo ao olhar do outro, deve mesmo ser o efeito produzido na interface com o olhar do outro, pois é nesta interface que ele ganha 'realidade' ou esmaece, caso não encontre o olhar que o 'realiza'.

"En bref, il faut se faire voir et être vu pour exister. Pour le dire autrement, on n'existe que dans et par le regard de l'autre" (Maffesoli, 2000, p. 158). Esta íntima relação entre existir, ver e ser visto é facilmente percebida nas votações que decidem o futuro dos participantes de reality shows, nas ferramentas de comentários dos weblogs e fotologs, por meio das quais os leitores e espectadores participam ativamente da escritura do texto e da composição da imagem que o autor constitui para si e para os outros (Recuero, 2003b), ou mesmo no número de amigos e 'cotações' dos membros do Orkut, onde o 'valor' de cada um está associado ao número de 'outros' que participam de sua 'comunidade' e às notas que eles lhe atribuem ${ }^{3}$.

Podemos perguntar sobre o grau de veracidade destas cotações do eu no olhar do outro; podemos perguntar se o que se atribui à superfície, à imagem tem alguma correspondência com uma profundidade, esta sim supostamente autêntica ou real. Ora, é preciso lembrar, e mais uma vez com
Maffesoli (1996, 1998b e 2000), que o jogo da aparência é também o jogo das máscaras, das formas, dos artifícios. A dinâmica da subjetividade e da sociabilidade contemporâneas pode ser melhor compreendida se estes termos forem tomados na sua efetividade, isto é, no seu poder de efetivar, constituir, formar, realizar, e não na tanto no seu poder de falsear ou mentir. É certo que mostrar, como nos faz ver a arte barroca, é também uma forma de esconder, mas na superficialidade estética pós-moderna o que é deixado para trás ou por trás da imagem, da aparência, da máscara e do artifício não é mais verdadeiro que o que se mostra.

Os critérios de veracidade ou autenticidade se deslocam com a crise das oposições artifício/natureza, aparência/essência, máscara/verdade. Os cuidados com o corpo contemporâneo, desde a cosmética às cirurgias plásticas, body buildings e transformismos de diversas ordens mostram que a experiência do corpo e seus investimentos afetivos e estéticos se voltam menos para o que ele é e para o que seriam os seus estados naturais, do que para o que ele pode vir a ser, o que nele pode ser transformado, esculpido, modelado. E tal experiência do corpo não pode ser facilmente definida como menos autêntica ou verdadeira, pois na ordem na aparência e da imagem, um corpo pode muito bem valer pelo que ele não é. Ou ainda, o que ele é reside cada vez mais naquilo que ele se torna e naquilo que dele se mostra e se dá a ver. É o que diz um personagem de Almodóvar a propósito de seu corpo pleno de silicone, um travesti que atende pelo nome extremamente sugestivo de Agrado: somos tão mais autênticos quanto mais próximos estivermos daquilo que desejamos ser. E neste mundo em que nossos corpos e almas ganham a plasticidade das imagens, a autenticidade também reside naquilo que se parece ser.

Deslizamos sem esforço no plano conceitual de Maffesoli e vemos agora o caráter efêmero, transitório e instantâneo de um cotidiano cuja ordem é a aparência e o visível. 
“La personne ... n'est qu'un masque (persona), ponctuel, jouant son rôle dans un ensemble dont elle est certes tributaire, mais dont elle pourra, demain, s'échapper pour dire et assumer une autre figure. Le pré-sentéisme est sa temporalité. Le paro-xysme, bien sûr, étant le déguisement des grands moments festifs ou, ce qui n'est pas très éloigné, les divers rituels de la 'haute couture'. Mais la vie quotidienne n'est pas elle non plus en reste, qui valorise la mode, le soin du corps et la diététique" (Maffesoli, 2000, p. 144).

Além da moda e dos cuidados com o corpo, as apresentações do eu no ciberespaço também inserem-se no fluxo movente das identidades incessantemente moduladas. Neste caso, a transitoriedade do euimagem é plenamente compatível com a 'natureza' do espaço que ele habita e dos signos sensíveis e visíveis que o compõem: pesquisas que acompanham o desenvolvimento de weblogs e fotologs mostram como muda-se constantemente as cores, as fotos, os fragmentos de texto e outros índices que expressem as transformações sem rastro das individualidades múltiplas e moventes (Recuero, 2003a). Nota-se ainda que os vínculos sociais nestes ambientes tendem a ser provisórios e mesmo instantâneos: tanto a sociabilidade entre bloggeiros quanto no Orkut mostram a constituição de comunidades extremamente efêmeras e de laços sociais que são feitos e desfeitos na velocidade do clique (Recuero, 2004).

Ainda que todos os exemplos mencionados ilustrem bem o que estamos tratanto, há um movimento recente da cena comunicacional onde todos os elementos vistos aqui encontram uma atualização paroxística - os chamados reality shows, 'de intervenção' ou 'de transformação' ${ }^{4}$. A obscenidade do cotidiano assume nestes programas uma forma nova e extrema, diferente do modelo de confinamento e vigilância do Big Brother, que já experimentou no Brasil uma receptividade excepcional.
Os reality shows de intervenção pululam na televisão brasileira e incluem programas de transformações mais ou menos profundas que vão desde mudanças no vestuário, na decoração da casa e na aparência (cortes de cabelo, lipoaspiração, liftings e peelings) a implantes de silicone, correções odontológicas e cirurgias plásticas ${ }^{5}$. Estas últimas podem se justificar por padrões estéticos ou de saúde (exemplos) ou por desejos os mais imaginários, como no caso do polêmico I want a famous face exibido pela MTV, cujo objetivo das cirurgias plásticas realizadas nos participantes é torná-los maximamente semelhantes aos seus ídolos midiáticos. Se o modelo do Big Brother ainda procurava revelar uma intimidade ou personalidade sob a cena testemunhada por uma vigilância idealmente ininterrupta, estes novos formatos parecem assumir que a verdade está mesmo na superfície e que a autenticidade reside na possibilidade de parecer outro, de tornar-se outro. "'É preciso mudar para que nos aceitemos como somos', ouvimos tantas vezes dos participantes" (Feldman, 2004). Apesar das diferenças entre os programas, se os tomamos em conjunto notamos a promoção de uma equivalência entre as diversas superfícies em jogo - corpo, pele, decoração, roupa, estilo, tela. A equivalência não é apenas de ordem espacial, mas também temporal - malgrado as suas diferenças materiais e 'de natureza', o corpo, a roupa e a tela gozam de níveis de efemeridade cada vez mais próximos uns dos outros. Os programas 'documentam' trajetórias individuais que se dividem entre o 'antes' e o 'depois', reproduzindo a estética vulgar das revistas femininas e a idéia de que primeiro é preciso parecer algo para depois ser e agir como tal (Feldman, 2004).

As íntimas relações entre o cotidiano, a aparência, o artifício e a efemeridade encontram neste ambiente comunicacional um exemplo extremo e grotesco. O fascínio e o interesse (por vezes mesclados com repúdio) que eles despertam nos nossos milhões de espectadores, refletem nossas manias e misérias. E nesta medida nos desafiam 
a ainda uma vez considerar um modo de olhar e de pensar sobre o qual Maffesoli não cessa de insistir: resistir ao apelo da denúncia impelida pelo 'dever-ser' e refletir, no âmbito mesmo do que se apresenta sobre o que nos é comum •

\section{Notas}

* Este artigo constitui um resultado do Projeto "As formas híbridas da cognição na atualidade", apoiado pela Fundação Universitária José Bonifácio/FUJB/UFRJ.

1 Dentre as diversas modalidades de weblogs (jornalística, literária, confessional etc), privilegiaremos aqueles que se assemelham a diários íntimos, onde se narra a vida cotidiana e se cultiva a expressão de si. Quanto aos fotologs, focalizaremos os que expõem imagens do eu e do cotidiano.

2 O Orkut é um software de constituição de ' redes sociais' ligado ao website de buscas Google (www.orkut.com). 0 software reúne pessoas e suas comunidades. As pessoas aí se apresentam na forma de perfis (constituídos de fotos, gostos e preferências pessoais, listas de amigos etc) e participam de comunidades. As comunidades são de diversos tipos, sendo que grande parte se constitui em torno do amor ou ódio a personalidades da cena midiática, cidades, programas de TV, filmes etc. Há também aquelas que reúnem pessoas com vínculos mais 'locais' ou 'territoriais', como habitantes de uma mesma cidade ou profissionais de uma mesma empresa ou área. Para ingressar no 'sistema' é preciso ser convidado por algum de seus membros. Cf. Fontanella, F. I. e Pryshton, A. "Trocando figurinhas: sobre Orkut, frivolidades, neotribalismo e flânerie" In: CDRom - Anais do XXVII Congresso Brasileiro de Ciências da Comunicação - Intercom, 2004.

3 No Orkut é possível saber o número de amigos que cada membro possui atestanto a sua 'popularidade' ou 'conectividade'. Além disso, qualquer um pode acrescentar comentários nas páginas de seus amigos, bem como atribuir notas a alguns de seus atributos (o quanto se é sexy, cool ou confiável).

4 Agradeço a Ilana Feldman por ter me apresentado com sagacidade a estes novos espetáculos do real. Cf. FELDMAN, Ilana "Intervenções "artísticas"?". Disponível em www. uol.com.br/tropico, 2004.
5 Dentre os programas que acompanham trajetórias de transformações 'leves', como decoração, vestuário, aparência e estilo, incluem-se, por exemplo, Antes e Depois (People + Arts), Missão MTV (MTV), Esquadrão da Moda (People + Arts), Minha casa, sua casa (People + Arts), Queer eye for the straight guy (Sony). Entre aqueles que documentam cirurgias plásticas, correções odontológicas e implantes de silicone estão Beleza Comprada (GNT), Extreme Makeover (Sony) e I want a famous face (MTV).

\section{Referências}

FELDMAN, Ilana "Intervenções "artísticas"?". Disponível em www.uol.com.br/tropico, 2004.

FONTANELLA, F. I. e PRYSHTON, A. "Trocando figu-rinhas: sobre Orkut, frivolidades, neotribalismo e flânerie". In: CD-Rom - Anais do XXVII Congresso Brasileiro de Ciências da Comunicação - Intercom 2004.

LEMOS, André. "A Arte da Vida. Webcams e Diários Pessoais na Internet". Revista Comunicação e Artes: a cultura das redes, 2001.

MAFFESOLI, Michel. No fundo das aparências. Petrópolis, RJ: Vozes, 1996.

0 tempo das tribos. Rio de janeiro: Forense, 1998a.

Elogio da razão sensível. Petrópolis, RJ: Vozes, 1998 b.

La conquête du présent, sociologie de la vie quotidienne. Paris: Desclée de Brower, 1998c.

L'instant éternel. Paris: Denoel, 2000.

"A comunicação sem fim" in Menezes-Martins, F. e da Silva, J. M. Genealogia do virtual. Porto Alegre: Sulina, 2004.

RECUERO, Raquel. "Weblogs Webrings e Comunidades Virtuais". Revista 404 NotFound. Edição 31, agosto de 2003. Disponível http://www.facom.ufba.br/ciberpesquisa/ 404nOtF0und/404 31.htm, 2003a.

"O Interdiscurso construtivo como característica fundamental dos Webrings". Disponível em pesquisa. http://www.pontomidia.com.br/raquel/pesquisa/, 
$2003 b$

"Teoria das redes e redes sociais na Internet: considerações sobre o Orkut, os weblogs e os fotologs". Trabalho apresentado no XXVII Congresso Brasileiro de Ciências da Comunicação - Intercom, 2004. 